\title{
Serum biomarkers of delirium in the elderly: a narrative review
}

\author{
Katharina Toft ${ }^{1,2}$, Janna Tontsch ${ }^{3}$, Salim Abdelhamid ${ }^{3}$, Luzius Steiner ${ }^{4,5}$, Martin Siegemund ${ }^{3,4+}$ \\ and Alexa Hollinger ${ }^{3 *}+$ D
}

\begin{abstract}
Delirium after surgery and in the intensive care unit (ICU) remains a challenge for patients, families, and caregivers. Over the years, many promising biomarkers have been investigated as potential instruments for risk stratification of delirium. This review aimed to identify and assess the clinical usefulness of candidate serum biomarkers associated with hospital delirium in patients aged 60 years and older. We performed a time-unlimited review of publications indexed in PubMed, Cochrane, Embase, and MEDLINE databases until June 2019 that evaluated baseline and/or longitudinal biomarker measurements in patients suffering from delirium at some point during their hospital stay. A total of 32 studies were included in this review reporting information on 7610 patients. Of these 32 studies, twentyfour studies reported data from surgical patients including four studies in ICU cohorts, five studies reported data from medical patients (1026 patients), and three studies reported data from a mixed cohort (1086 patients), including one study in an ICU cohort. Findings confirm restricted clinical usefulness to predict or diagnose delirium due to limited evidence on which biomarkers can be used and limited availability due to non-routine use.
\end{abstract}

\section{Introduction}

Postoperative and intensive care unit (ICU) delirium remains a challenge for patients, families, and caregivers. Identified more than half a century ago in cardiac surgery patients, delirium today is characterized by criteria of the Diagnostic and Statistical Manual of Mental Disorders (DSM)-V, which can be summarized as a fluctuating disturbance of consciousness evolving over a short period of time, a change in cognition, and evidence from the current history, physical examination, or laboratory findings that the disturbance is caused by the direct physiological consequences of a general medical condition.

The suffering of delirious patients is severe as they may be restless, hallucinate, and be filled with fear. Unfortunately, problems continue even after the resolution of delirium. This syndrome may be associated with prolonged ICU and hospital stay [1, 2], more hospital

\footnotetext{
*Correspondence: alexa.hollinger@usb.ch

${ }^{\dagger}$ Martin Siegemund and Alexa Hollinger have contributed equally to this work

${ }^{3}$ Department for Intensive Care, University Hospital Basel, Basel, Switzerland

Full list of author information is available at the end of the article
}

readmissions [3], reduced quality of life, loss of independence, and increased mortality [1,4-7]. Furthermore, the duration of delirium is associated with worse longterm cognitive function $[8,9]$. The increased socioeconomic burden should also not be underestimated [10]. However, a recently updated delirium guidance paper on prevention and management of pain, agitation/sedation, delirium, immobility, and sleep disruption in adult ICU patients summarizes that delirium in critically ill adults has not been consistently shown to be associated with ICU length of stay, discharge disposition to a place other than home, depression, functionality/dependence, or mortality [11].

Ranging from 10 to $80 \%$ [12-14] or even up to $90 \%$ depending on the type of surgery [15], the overall incidence of delirium is high during hospital stay, especially in elderly patients. Delirium usually develops within $72 \mathrm{~h}$ after surgery and/or ICU admission. However, its impact is likely to be underestimated due to the predominance of hypoactive delirium.

Although the pathophysiology of delirium remains poorly understood, we know that the pathogenesis of the cognitive impairments associated with delirium is 
multifactorial. Certain entities such as drug overdose [16] but also drug withdrawal [17] bear delirium risk. As with so many disparate etiologies, it is highly unlikely that a single mechanism is solely responsible [18]. Therefore, research focuses on the assessment of modifiable pre-, intra-, and postoperative risk factors (e.g., dehydration, fluid balance, immobilization, analgesia, and sleep deprivation) associated with delirium, [18] as well as prediction, prevention, early detection, and treatment of this common psychiatric syndrome. One promising approach is the detection of elevated or lowered biomarkers as predictors or indicators of delirium [19, 20]. Furthermore, serum biomarkers may aid in risk stratification, diagnosis, and monitoring of delirium [19] and, finally, may help to find an effective treatment. This review aims to summarize the current state of knowledge on serum biomarkers of delirium.

\section{Methods}

We performed an updated review on biomarkers of delirium based on previous publications [19]. As age is one of the most consistently reported risk factors for developing delirium, we restricted our search to publications including patients aged 60 years and older [18, 21]. Study selection and quality assessment were performed by two independent authors (AH and $\mathrm{KT}$ ). The results were compared, and disagreements were reviewed (MS).

\section{Literature search}

An electronic search of PubMed, Cochrane, Embase, and MEDLINE databases was performed. The detailed search strategy is available in "Appendix" (Additional files). Search terms used for each biomarker are listed in Additional file 1: Table S1. Every biomarker term according to Additional file 1: Table S1 was searched with "delirium", "acute brain dysfunction", "stroke", "hemorrhagic stroke", "ischemic stroke", "traumatic brain injury", and "septic encephalopathy". The date of the last search was June 1 , 2019.

\section{Inclusion and exclusion criteria}

Only studies that met the following criteria were included: patients aged 60 or older, sample size of 10 or higher, use of standardized approach to diagnose delirium [e.g., Intensive Care Delirium Screening Checklist (ICDSC), Confusion Assessment Method (CAM or CAM-ICU); Nursing Delirium Screening Scale (NuDESC); Delirium Observation Screening Scale (DOS); Diagnostic and Statistical Manual of Mental Disorders (DSM)-III/IV; Delirium Symptom Interview (DSI); Delirium Rating Scale Revised-98-T (DRS-R98-T); Memorial Delirium Assessment Scale (MDAS)], ICU/ hospital cohort (e.g., excluding studies performed in nursing homes), and English language. Reviews from all cohorts (i.e., medical, surgical, mixed, ICU) were included. Age limitation was chosen due to significantly higher reported incidence of delirium in patients 60 to 65 and older, and to help clarify results within the flood of information on delirium biomarkers available to date for the age category at highest risk. Studies reporting data that included patients with cognitive dysfunction due to preexisting psychiatric disorders, known dementia, or alcohol-related delirium (delirium tremens) were excluded. Reviews/meta-analyses, and studies reporting animal data or cerebrospinal fluid (CSF) biomarkers were also excluded.

\section{Data extraction}

Study-relevant information was extracted by two independent investigators (AH and KT) for each included study. Any conflict of opinion was resolved by consensus with a third party (MS). Study location and date of study conduct, patient characteristics, past medical history including drug therapy prior to hospitalization, risk assessment scores (e.g., Charlson comorbidity index), outcome data (i.e., ICU and hospital length of stay, mortality), total number of patients, and study-specific procedures-including drug therapy during ICU and/or hospital stay-were considered relevant for data extraction. Observational and interventional study design was distinguished.

\section{Results \\ Trial identification}

In June 2019, a search of the PubMed, Cochrane, Embase, and MEDLINE databases using the search terms "delirium", "acute brain dysfunction", "stroke", "hemorrhagic stroke", "ischemic stroke", "traumatic brain injury", and "septic encephalopathy" [22] AND "biomarker" (term "biomarker" and each biomarker suggested by the authors, Additional file 1: Table S1) for papers published until June 1, 2019, retrieved 1839 publications (Fig. 1). After removal of 57 duplicates, a critical review of the titles and abstracts was performed, and another 616 articles without study-specific data were excluded. Thirtytwo studies (29 observational and three interventional) remained after further exclusion of 1134 articles based on title, abstract, or full text as indicated in Fig. 1. The full texts of these remaining studies (Table 1) were reviewed for data extraction by two independent investigators (AH and KT). Due to age limitation a total of 73 publications on mostly mixed populations (sample size ranging from 10 to 1183 ) and 34 publications on the pediatric cohort have been excluded from our analysis (Fig. 1). 


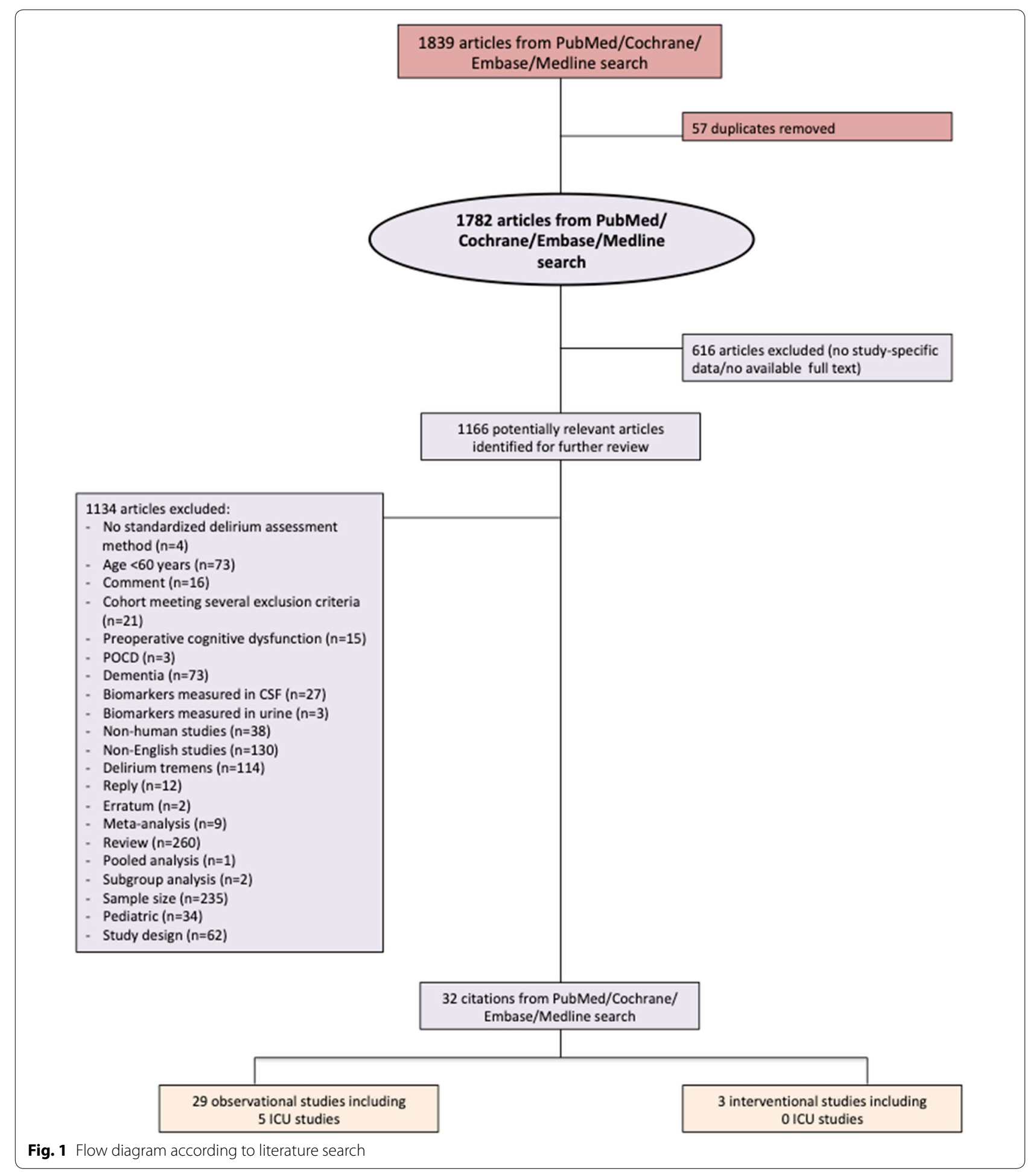

\section{Study characteristics}

All 32 studies were published before May 2019 and included information on 7610 patients. Twenty-four studies reported data from surgical patients [23-46], of which two studies analyzed the same patient cohort [29,
30]. Of these 24 studies, 12 reported data collected from delirium high-risk surgical cohorts: Two studies reported data from cardiac surgery $[39,42]$, and ten reported data from hip surgery patients $[23,24,28,32,33,35-37,41$, 45]. Five studies reported data from medical patients 


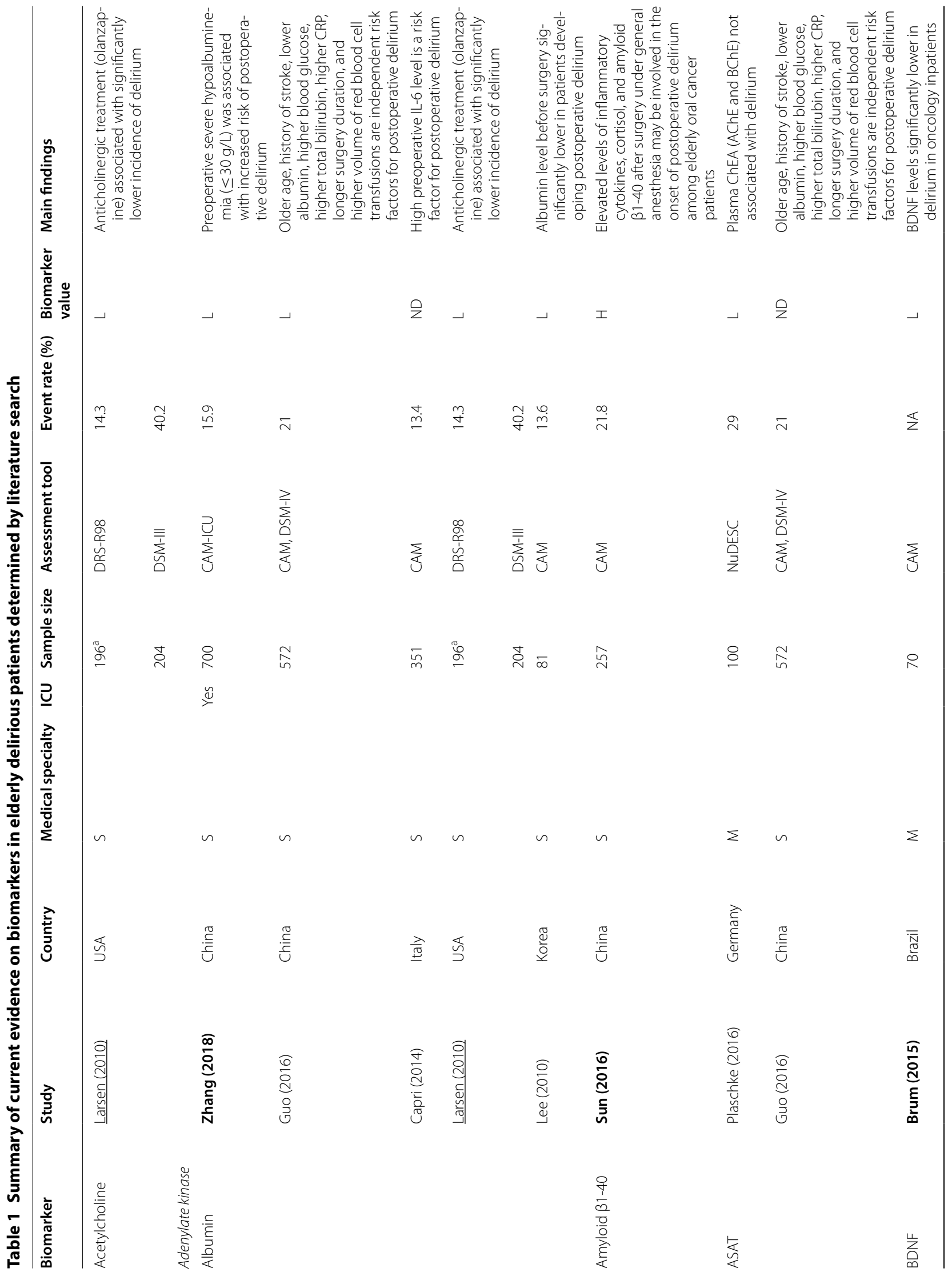




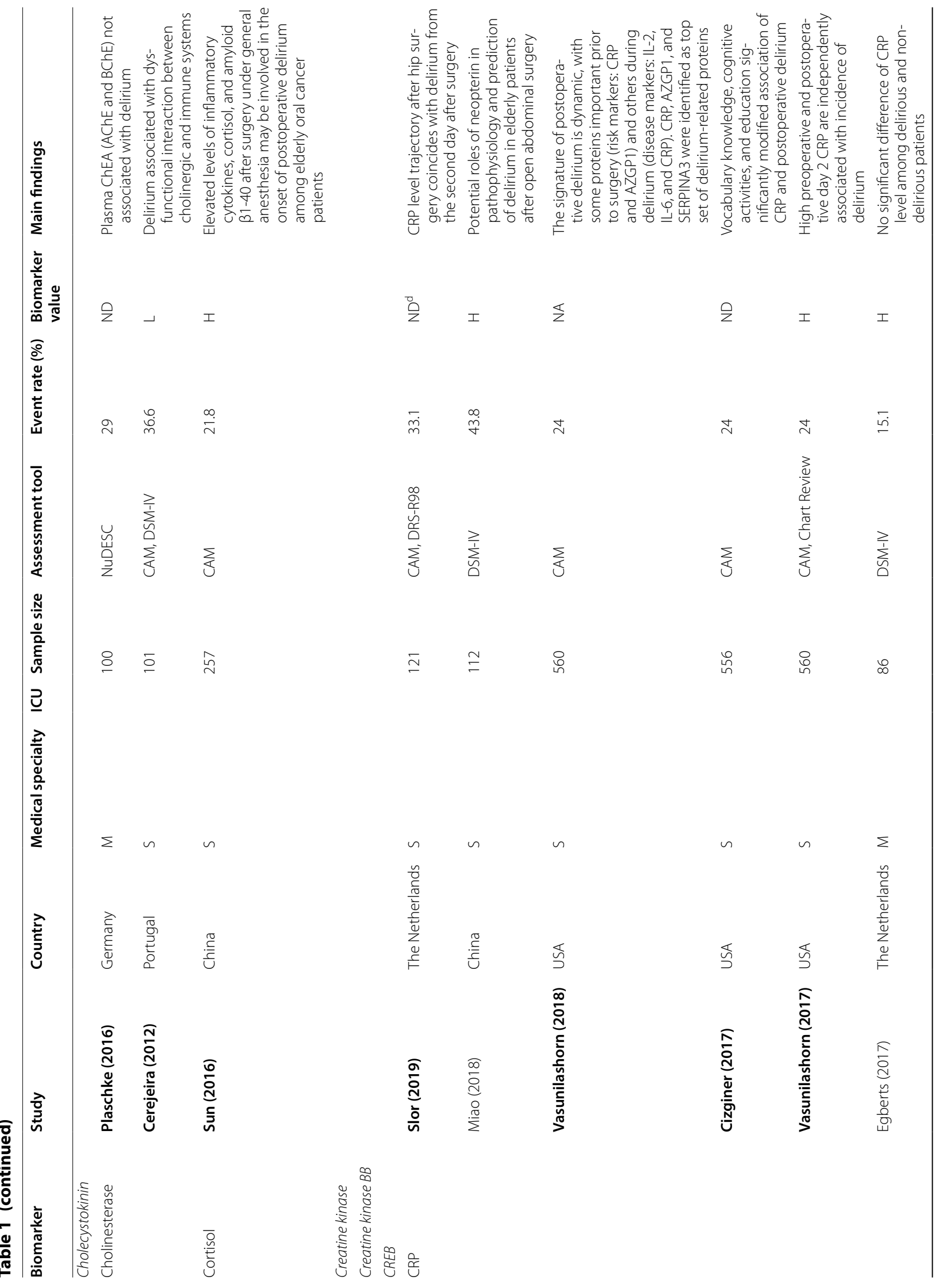




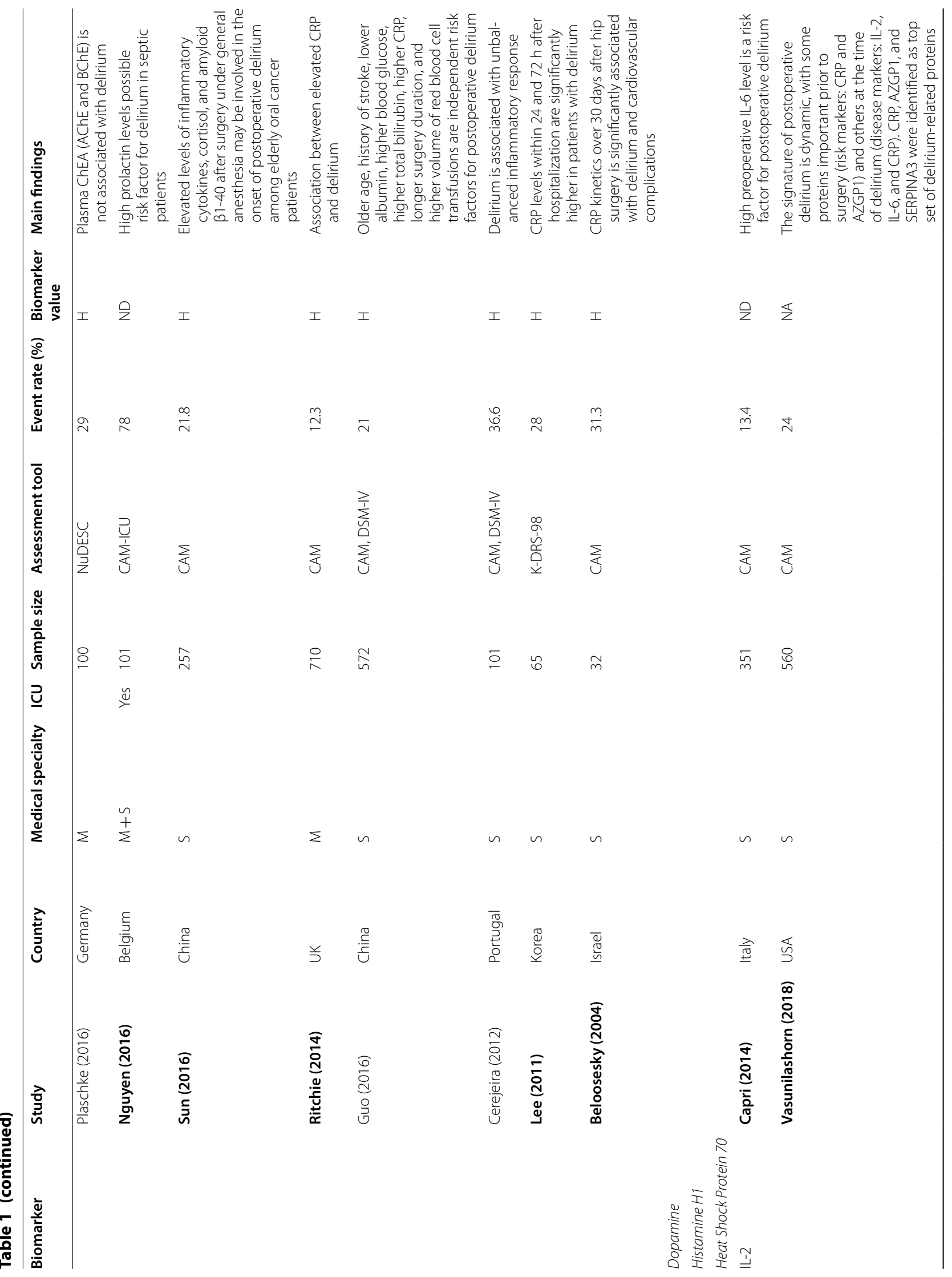




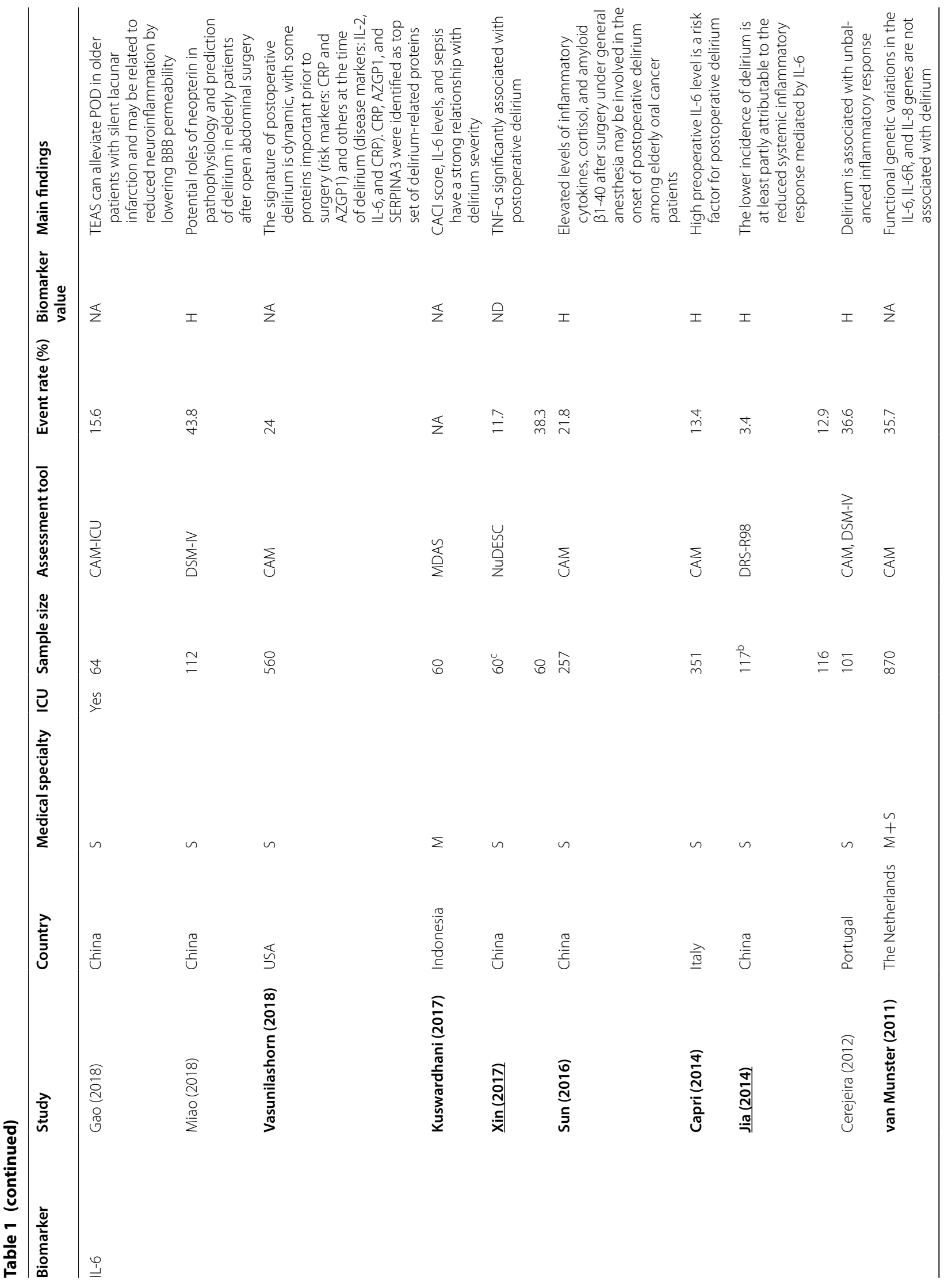




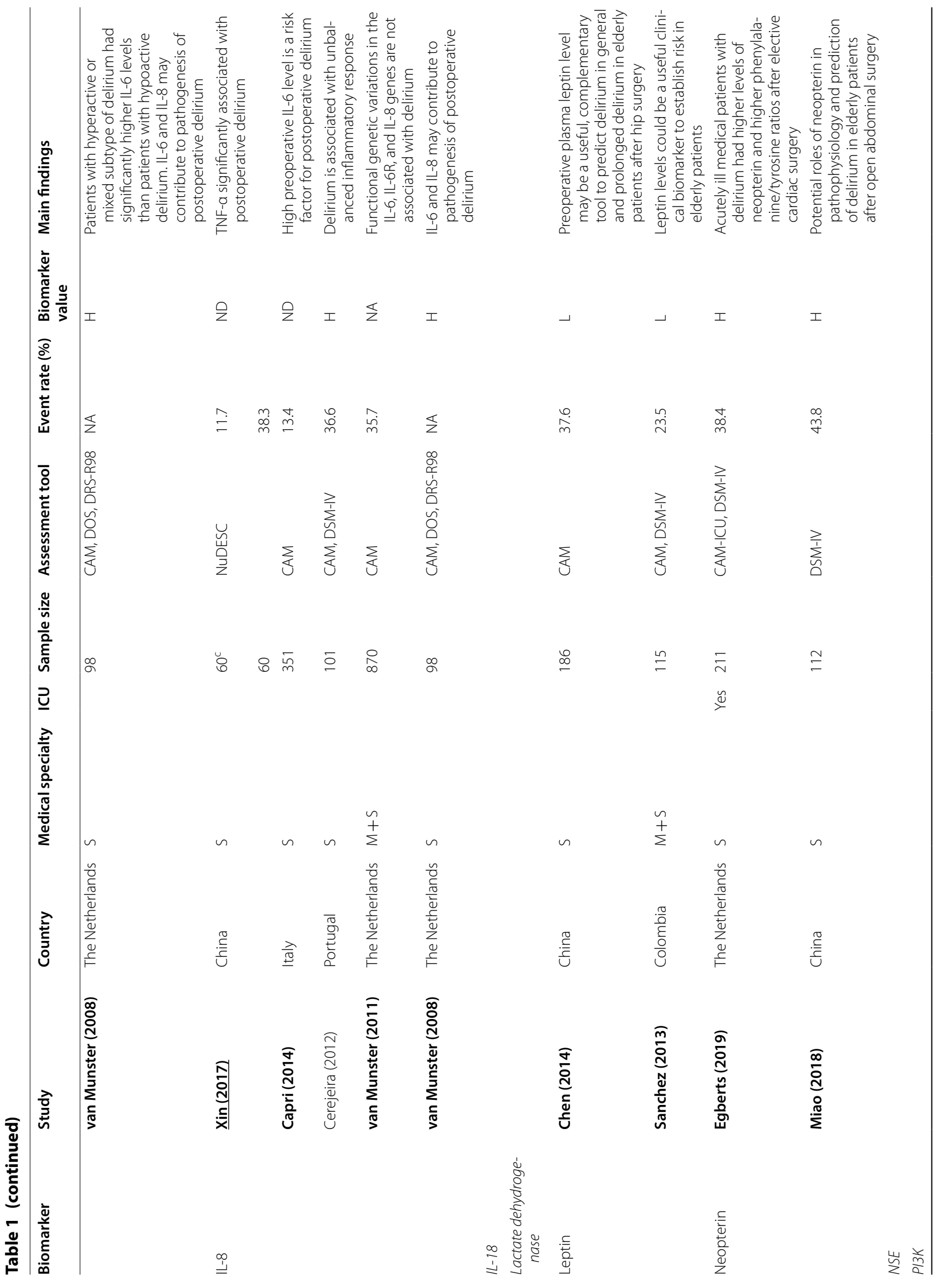




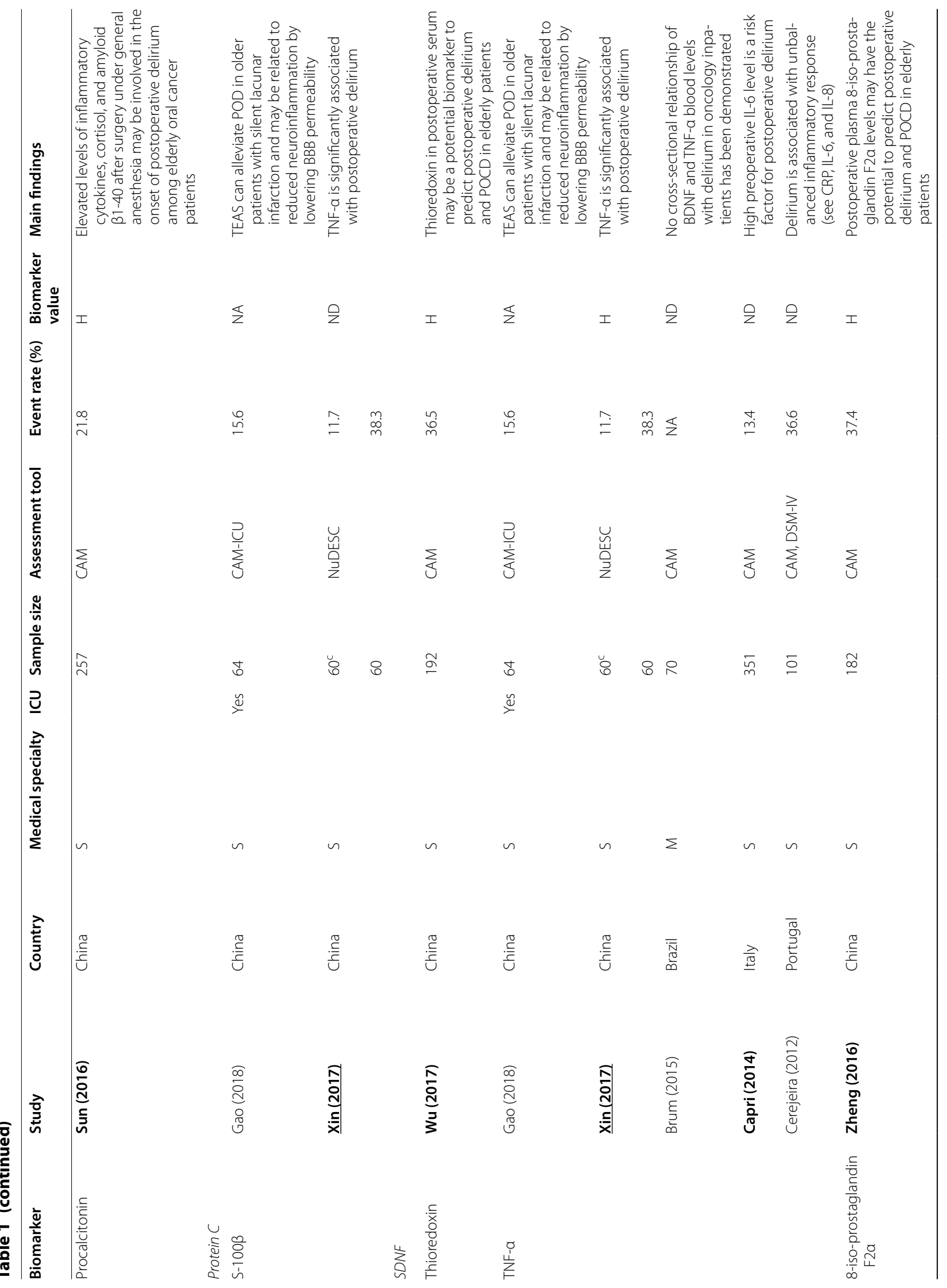




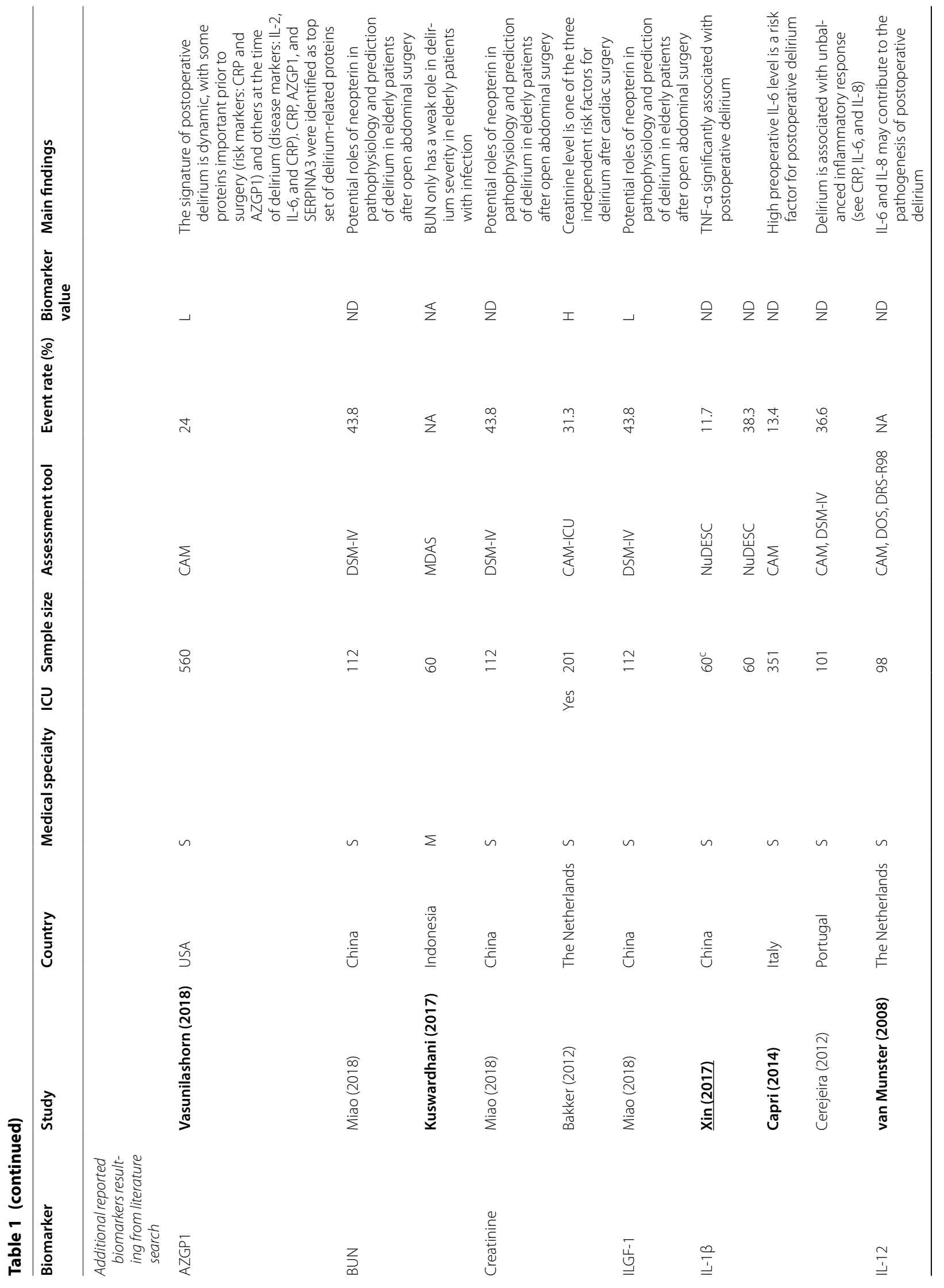




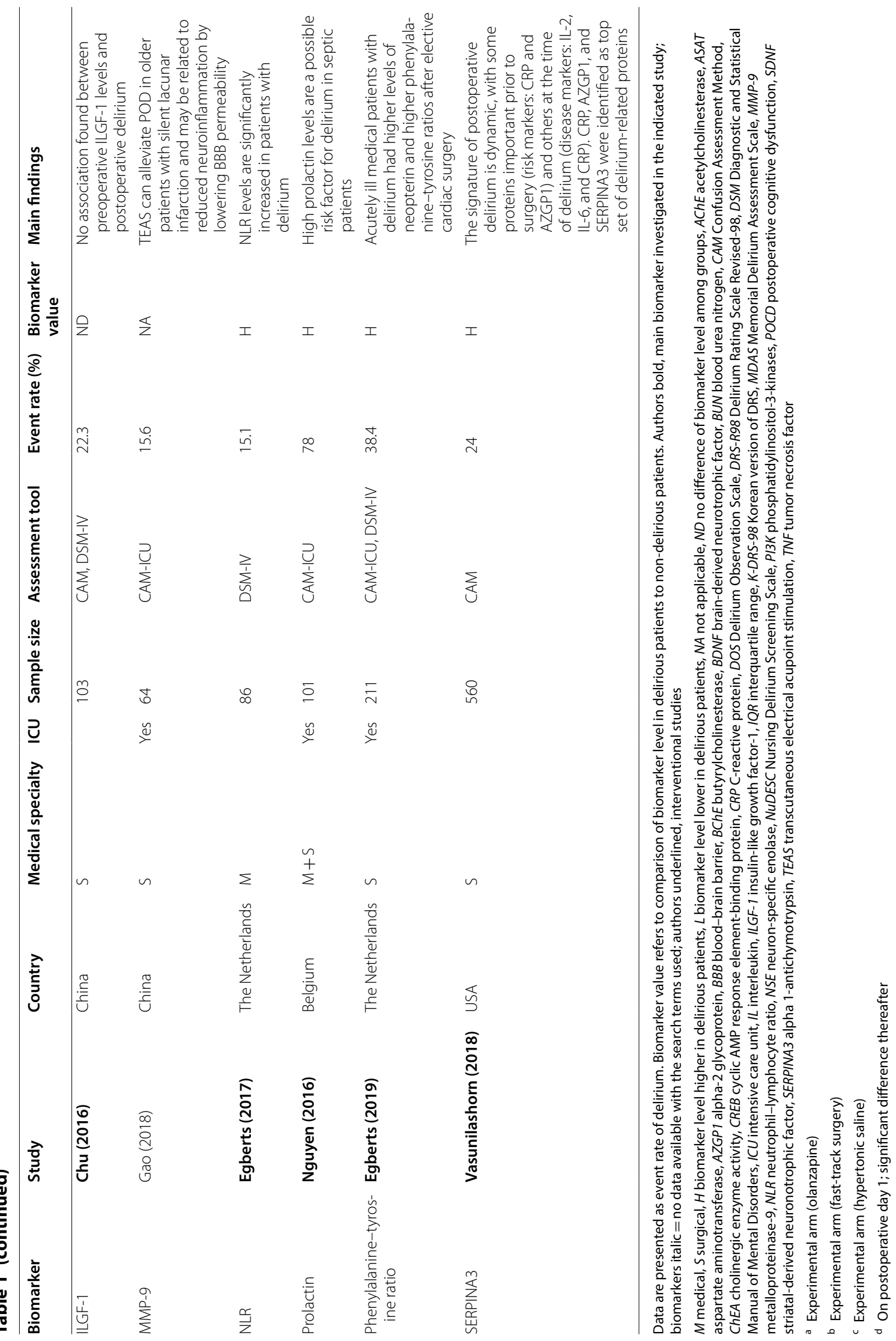


(1026 patients) [47-51], and three studies reported data from a mixed cohort (i.e., surgical and medical patients or not defined; 1086 patients) [52-54]. Twenty-nine were observational studies, and three were interventional studies (outlined in more detail below).

\section{Biomarkers}

The authors initially screened for biomarkers already known as possible markers of delirium (Additional file 2: Table S2). A second comprehensive screening of the literature was for biomarkers mentioned particularly in the context of other neurological diseases, but bearing a possible association with delirium, including dementia, delirium tremens, hypoxic brain injury, and Parkinson's disease (Additional file 2: Table S2). These searches resulted in 11 additional biomarkers that were also investigated in the context of delirium in the elderly (Additional file 2: Table S2).

Biomarkers were grouped according to their biochemical function (i.e., cytokine, enzyme, growth factor, hormone, metabolic product, neuronotrophic factor, neurotransmitter, transcription factor, transport protein, or other; Table 2). Overall, 20 biomarkers were reported to detect or to be associated with delirium (Table 3). Of these, higher levels of 14 biomarkers [i.e., IL-6, cortisol, prolactin, amyloid, creatinine, C-reactive protein (CRP), neopterin, metalloproteinase-9 (MMP-9), neutrophillymphocyte ratio (NLR), phenylalanine-tyrosine ratio, procalcitonin, thioredoxin, serpin family A member 3 (SERPINA3 (alpha 1-antichymotrypsin)), and 8-isoprostaglandin F2 $\alpha$ ] and lower levels of 6 biomarkers [i.e., brain-derived neurotrophic factor (BDNF), leptin, acetylcholine, albumin, insulin-like growth factor-1 (ILGF1 ), and alpha-2 glycoprotein (AZGP1)] were reported in delirious patients. However, apart from CRP clinical relevance of the presented biomarkers was either questioned or denied by the authors (Table 3). With the exception of IL-1 $\beta$ and IL-12 all inflammatory biomarkers could be linked to delirium (Additional file 3: Table S3; Additional file 4: Table S4). Moreover, a connection to delirium was found for all four biomarkers of metabolism (Additional file 3: Table S3; Additional file 4: Table S4).

\section{Surgical cohort}

Overall, 19 studies reported on the incidence of delirium. Event rate of postoperative delirium ranged from 13.4 to $43.8 \%$ (Table 1). Four studies reported data from ICU patients (delirium incidence range 15.8 to $43.8 \%$; Table 1 ) [39]. Within the studies reporting data from surgical patients, three were interventional and as such did not group patients into delirious and non-delirious prior to investigation. Each of these three studies showed a lower incidence of delirium in the experimental arm (Table 1):
One compared olanzapine to placebo (delirium incidence $14.3 \%$ vs. $40.2 \%$ ) [23], one compared fast-track surgery to the standard procedure (delirium incidence $3.4 \%$ vs. $12.9 \%$ ) [34], and one compared hypertonic to normal saline (delirium incidence $11.7 \%$ vs. $38.3 \%$ ) [33].

\section{Biomarker assessment of postoperative delirium}

Biomarkers reported from investigations of surgical cohorts are shown in Table 1. Two studies from the surgical population and one from the medical population evaluated the role of the acetylcholine pathway in delirium. Whereas anticholinergic treatment was suggested as a promising strategy to reduce the incidence of delirium [23], reports on cholinesterase were not as clear [28]. Albumin was the main focus of one study [43], but also evaluated in four other studies resulting from our literature search [23-26]. It was almost consistently reported to be lower in delirious patients. Amyloid $\beta 1-40$, a protein associated with dementia, was the main focus of Sun and colleagues [27] who reported a possible role in the detection of delirium. No difference in ASAT was found among postoperatively delirious and non-delirious patients. Like albumin, ASAT was not the focus of the study cited here [24]. Among inflammatory markers, increased procalcitonin [27], CRP [24, 27, 28, $30-32,41,45,46]$, and IL-6 [25, 27, 28, 34, 35, 44, 46] were consistently reported to be associated with delirium with the exception of one study that found no increase in IL-6 levels [33]. Of note, in this study, IL-6 was collected early (i.e., venous blood was drawn at 06:00 on the first day after surgery). Cortisol [27] and leptin were the two reported hormones with a possible link to postoperative delirium. Leptin levels were significantly lower in patients with delirium compared to those without [36]. Finally, AZGP1 [29], MMP-9 [44], neopterin [42], phenylalanine-tyrosine ratio [42], SERPINA3 [29], thioredoxin [37], and 8-iso-prostaglandin F2 $\alpha$ [38] were linked to postoperative delirium.

\section{Medical cohort}

Within the studies reporting data from medical patients, three studies reported an incidence of delirium ranging from 12.3 to $29 \%$ (Table 1 ).

\section{Biomarker assessment of delirium in elderly patients admitted for medical reasons}

Biomarkers reported from investigations on patients admitted for medical reasons are outlined in Table 1 . The study reporting results on the assessment of cholinesterases (i.e., acetylcholinesterase and butyrylcholinesterase) in medical patients found no association with delirium [47]. As opposed to the surgical cohort, ASAT was found to be lower in delirious patients admitted for medical 
Table 2 Grouping of suggested biomarkers of delirium according to their main function

\begin{tabular}{|c|c|c|}
\hline Function & Assigned biomarker & Established clinical use \\
\hline \multirow[t]{7}{*}{ Cytokine } & $\| \mathrm{L}-1 \beta$ & Inflammatory marker \\
\hline & $\mathrm{IL}-2$ & \\
\hline & IL-6 & \\
\hline & IL-8 & \\
\hline & $\mathrm{IL}-12$ & \\
\hline & IL-18 & \\
\hline & TNF-a & \\
\hline \multirow[t]{8}{*}{ Enzyme } & Adenylate kinase & Marker of liver cell damage \\
\hline & ASAT & Marker of cell damage \\
\hline & Cholinesterase & Marker of liver synthetic function \\
\hline & CK & Marker of muscle damage \\
\hline & CK-BB & Tumor marker \\
\hline & LDH & Marker of tissue breakdown \\
\hline & NSE & Tumor marker; brain damage marker \\
\hline & $\mathrm{Pl} 3 \mathrm{~K}$ & \\
\hline \multirow[t]{2}{*}{ Growth factor } & BDNF & Diagnosis of growth hormone deficiency; marker of pituitary function \\
\hline & IGF-1 & \\
\hline \multirow[t]{4}{*}{ Hormone } & Cholecystokinin & \\
\hline & Cortisol & Marker of adrenal function \\
\hline & Leptin & \\
\hline & Prolactin & $\begin{array}{l}\text { Marker of pituitary gland/hypothalamus function; fertility assessment; } \\
\text { tumor marker }\end{array}$ \\
\hline \multirow[t]{2}{*}{ Metabolic product } & Amyloid & \\
\hline & Phenylalanine-tyrosine ratio & \\
\hline \multirow[t]{2}{*}{ Neuronotrophic factor } & S-100ß & Tumor marker; brain damage marker \\
\hline & SDNF & \\
\hline \multirow[t]{3}{*}{ Neurotransmitter } & Acetylcholine & \\
\hline & Dopamine & \\
\hline & Histamine & \\
\hline Transcription factor & CREB & \\
\hline Transport protein & Albumin & Nutritional marker, negative acute phase protein \\
\hline \multirow[t]{12}{*}{ Other } & AZGP1 & \\
\hline & BUN & Marker of kidney function \\
\hline & Creatinine & Marker of kidney function \\
\hline & CRP & Inflammatory marker, positive acute phase protein \\
\hline & HSP70 & \\
\hline & Metalloproteinase-9 & Proinflammatory marker \\
\hline & Neopterin & Marker of infection \\
\hline & NLR & \\
\hline & Procalcitonin & Proinflammatory marker \\
\hline & Protein C & \\
\hline & Thioredoxin & \\
\hline & 8-iso-prostaglandin F2a & \\
\hline
\end{tabular}

$A S A T$ aspartate aminotransferase, $A Z G P 1$ alpha-2 glycoprotein, $B D N F$ brain-derived neurotrophic factor, $B U N$ blood urea nitrogen, $C K$ creatine kinase, $C K$-BB creatine kinase BB, CREB cyclic AMP response element-binding protein, CRP C-reactive protein, HSP70 heat shock protein 70, IL interleukin, IGF-1 insulin-like growth factor-1, LDH lactate dehydrogenase, NLR neutrophil-lymphocyte ratio, NSE neuron-specific enolase, PI3K phosphatidylinositol-3-kinases, $P C T$ procalcitonin, SDNF striatalderived neuronotrophic factor, TNF tumor necrosis factor 
Table 3 Role of suggested biomarkers of delirium according to literature reports

\begin{tabular}{|c|c|c|c|}
\hline Function & Assigned biomarker & $\begin{array}{l}\text { Biomarker } \\
\text { of delirium }\end{array}$ & $\begin{array}{l}\text { Clinically } \\
\text { useful }\end{array}$ \\
\hline \multirow[t]{7}{*}{ Cytokine } & $\mathbb{I L}-1 \beta$ & - & - \\
\hline & $\mid \mathrm{IL}-2$ & $?$ & - \\
\hline & IL-6 & + & - \\
\hline & IL-8 & $?$ & - \\
\hline & $\mathrm{IL}-12$ & - & \\
\hline & IL-18 & $N R$ & - \\
\hline & TNF-a & $?$ & - \\
\hline \multirow[t]{8}{*}{ Enzyme } & Adenylate kinase & NR & - \\
\hline & ASAT & $?$ & - \\
\hline & Cholinesterase & $?$ & - \\
\hline & CK & $N R$ & - \\
\hline & CK-BB & $N R$ & - \\
\hline & $\mathrm{LDH}$ & $N R$ & - \\
\hline & NSE & $N R$ & - \\
\hline & PI3K & $N R$ & - \\
\hline \multirow[t]{2}{*}{ Growth factor } & BDNF & + & - \\
\hline & ILGF-1 & + & - \\
\hline \multirow[t]{4}{*}{ Hormone } & Cholecystokinin & $N R$ & - \\
\hline & Cortisol & + & - \\
\hline & Leptin & + & - \\
\hline & Prolactin & + & - \\
\hline \multirow[t]{2}{*}{ Metabolic product } & Amyloid & + & $?$ \\
\hline & $\begin{array}{l}\text { Phenylalanine-tyrosine } \\
\text { ratio }\end{array}$ & + & $?$ \\
\hline \multirow[t]{2}{*}{ Neuronotrophic factor } & $S-100 \beta$ & - & - \\
\hline & SDNF & $N R$ & - \\
\hline \multirow[t]{3}{*}{ Neurotransmitter } & Acetylcholine & + & - \\
\hline & Dopamine & NR & - \\
\hline & Histamine & $N R$ & - \\
\hline Transcription factor & CREB & $N R$ & - \\
\hline Transport protein & Albumin & + & $?$ \\
\hline \multirow[t]{13}{*}{ Other } & AZGP1 & + & - \\
\hline & BUN & $?$ & - \\
\hline & Creatinine & + & $?$ \\
\hline & CRP & + & + \\
\hline & HSP70 & $N R$ & - \\
\hline & Metalloproteinase-9 & + & $?$ \\
\hline & Neopterin & + & $?$ \\
\hline & NLR & + & $?$ \\
\hline & Procalcitonin & + & $?$ \\
\hline & Protein C & $N R$ & - \\
\hline & Thioredoxin & + & - \\
\hline & SERPINA3 & + & - \\
\hline & 8-iso-prostaglandin F2a & + & - \\
\hline
\end{tabular}

$N R$ nothing reported in the literature, + correlation with delirium, - no correlation with delirium, ASAT aspartate aminotransferase, AZGP1 alpha-2 glycoprotein, BDNF brain-derived neurotrophic factor, $B U N$ blood urea nitrogen, CREB cyclic AMP response element-binding protein, CRP C-reactive protein, IL interleukin, ILGF-1 insulin-like growth factor-1, NLR neutrophil-lymphocyte ratio, NSE neuron-specific enolase, PI3K phosphatidylinositol-3-kinases, SDNF striatalderived neuronotrophic factor, SERPINA3 alpha 1-antichymotrypsin, TNF tumor necrosis factor reasons [47]. Lower BDNF levels were clearly linked to delirium in oncology patients [48]. Findings on CRP $[47,49,50]$ and IL-6 [51] concurred with those reported from the surgical cohorts. NLR was additionally linked to delirium [49].

\section{Mixed cohort}

The three studies to report data from both, medical and surgical patients, reported a combined incidence of delirium of 23.5\% (Sanchez [54]) and 35.7\% (Van Munster [53]) in non-ICU patients, and of 78\% (Nguyen [52]) in ICU patients with sepsis (Table 1).

\section{Biomarker assessment of delirium in mixed cohorts of elderly patients}

Biomarkers reported from investigations of mixed cohorts are also outlined in Table 1. The two markers reported to have a possible association with delirium in mixed patient cohorts were leptin [54] and prolactin (ICU cohort; [52]).

\section{Discussion}

Our updated findings are consistent with a review published 7 years ago, in 2011, by Khan and colleagues [19] who had reported a lack of evidence for the clinical use of biomarkers to aid in earlier detection, prevention, or treatment of delirium. As long as there are no adequate means of intervention, altered levels of biomarkers are unlikely to initiate any change in clinical practice. So far, no biomarker has been identified that would enable development of treatment strategies to lower the incidence, severity, or duration of delirium. A useful biomarker needs to be easily identifiable and reliable to enable targeted therapy while being cost-effective. These criteria were not applicable for any biomarker found in this literature review. Of note, we only reported data from patients aged 60 and older, as opposed to the review by Khan and colleagues [19].

Our main conclusion that none of the biomarkers described help to lower the incidence of delirium is based on several considerations. Pathophysiological explanations such as those addressed by the neurotransmitter hypothesis have already been described nearly 40 years ago [55]. Despite the knowledge of the role of neurotransmitters in the pathophysiology of delirium, with central cholinergic deficiency remaining the leading hypothesis [56], we have not yet been able to find a way to decrease the incidence of delirium. Dopamine excess and inflammation are important assumptions competing with or contributing to the hypothesis of cholinergic deficiency [57], but the focus should lie on modifiable factors causing delirium [18]. This includes stress reduction due to minimization of light and noise disturbances 
at night and adequate pain management among other things, but also preventive drug therapy in high-risk cohorts $[58,59]$. Most importantly, the pathophysiology of delirium remains poorly understood [60] despite being first described by Hippocrates more than 2500 years ago [61]. So on the one hand, our findings are consistent with established theories such as the role of neurotransmitters, inflammation, and stress response in delirium (i.e., reported association of acetylcholine, IL-6, CRP, procalcitonin, and cortisol). On the other hand, there are new approaches that, however, lack sufficient evidence or validation for implementation into everyday clinical practice (i.e., BDNF, leptin, MMP-9, neopterin, phenylalaninetyrosine ratio, prolactin, NLR, thioredoxin, 8-iso-prostaglandin F2 $\alpha$, AZGP1, and SERPINA3). As such, the latter are not readily available. Delirium biomarkers that are included in standard blood examinations (i.e., albumin and creatinine) may be useful to attribute higher delirium risk but are not targets specific to delirium prevention since they are routinely addressed with respect to other clinical questions. It is nevertheless interesting that an elevated creatinine level was reported to be an independent risk factor for delirium in a cardiac surgery cohort; clinicians should keep this in mind [39].

An almost exclusive association of the numerous investigated inflammatory biomarkers with delirium offers room for and discussion on a novel approach: The implementation of a widely used inflammatory marker (i.e., CRP or procalcitonin) as a diagnostic tool might help facilitate diagnosis of hypoactive delirium. The same can be said for biomarkers of metabolism. Moreover, these biomarkers could be implemented into a tool to assess delirium risk. Finally, the accepted role of amyloid $\beta 1-40$ for delirium risk has also been confirmed. But clinical relevance here can be reduced to knowledge of its existence, since patients suffering from dementia are known to bear higher risk of delirium [62].

We acknowledge the following limitations of the presented review. First, we did not include any reports on biomarkers with a sample size lower than 10. Important biomarkers to be further explored in larger cohorts may thus have escaped our attention. Second, we focused on patients aged 60 and older, which led to the exclusion of numerous publications reporting other potentially important biomarkers for the elderly population including key articles on delirium biomarkers [63-68]. Interestingly, putative delirium biomarkers such as NSE and $\mathrm{S}-100 \beta$ were reported/found to be irrelevant [59]. Third, there is an imbalance between medical and surgical patients investigated. In addition, high-risk surgical groups (i.e., hip and cardiac surgery) are overrepresented, whereas another important high-risk group (i.e., ICU patients) is underrepresented in the reported literature.
Last, all observational studies have outlined biomarker levels comparing delirious to non-delirious patients. Overall, delirium is diagnosed clinically by established delirium assessment methods and biomarker groups and could be helpful to diagnose patients where a delirium is not so obvious (i.e., hypoactive delirium). In addition, it is not easy to influence levels of the biomarkers reported here other than by following guidelines (e.g., hygiene directives, pain control, prevention and management of infections, avoidance of unnecessary surgery, and adequate nutrition).

\section{Conclusion}

The concluding observations offer no ground-breaking recommendation for the implementation of a specific biomarker of delirium. Inflammatory biomarkers and biomarkers of metabolism could assist in diagnosing delirium and in assessing delirium risk. Expert opinions state that especially the hypoactive form is frequently undiagnosed even when using established tools to diagnose delirium. The implementation of these biomarkers in delirium assessment tools could represent a new approach. However, authors found inflammatory biomarkers not consistently reported as delirium risk factors. Their level of evidence should first be investigated in a meta-analysis.

\section{Additional files}

Additional file 1: Table S1. Terms used for biomarker search in alphabetical order.

Additional file 2: Table S2. Overview of biomarkers investigated in this review including references.

Additional file 3: Table S3 Role of inflammatory and metabolic biomarkers in delirium according to literature reports.

Additional file 4: Table S4 Sensitivity and specificity analysis of inflammatory biomarkers and biomarkers of metabolism that could assist in diagnosing delirium and in assessing delirium risk.

\section{Abbreviations}

ASAT: aspartate aminotransferase; AZGP1: alpha-2 glycoprotein; BDNF: brainderived neurotrophic factor; BUN: blood urea nitrogen; CK: creatine kinase; CK-BB: creatine kinase BB; CAM: Confusion Assessment Method; DRS-R98-T: Delirium Rating Scale Revised-98-T; CREB: cyclic AMP response elementbinding protein; CRP: C-reactive protein; DOS: Delirium Observation Screening Scale; DRS: delirium rating scale; DSI: Delirium Symptom Interview; DSM: Diagnostic and Statistical Manual of Mental Disorders; H1: histamine type 1; HSP: heat shock protein; ICB: intracerebral bleeding; ICDSC: Intensive Care Delirium Screening Checklist; ICU: intensive care unit; LDH: lactate dehydrogenase; MDAS: Memorial Delirium Assessment Scale; MoCA: Montreal Cognitive Assessment; NLR: neutrophil-lymphocyte ratio; NSE: neuron-specific enolase; NUDESC: Nursing Delirium Screening Scale; PI3K: phosphatidylinositol3-kinases; POD: postoperative delirium; SDNF: striatal-derived neuronotrophic factor; SERPINA3: serpin family A member 3 (alpha 1-antichymotrypsin); TNF: tumor necrosis factor. 
Acknowledgements

We thank Allison Dwileski for editing the manuscript.

\section{Authors' contributions}

$\mathrm{AH}$ and $\mathrm{MS}$ conceived or designed the work. $\mathrm{AH}, \mathrm{JT}, \mathrm{KT}$, and SA performed the literature study; $\mathrm{AH}$ and $\mathrm{KT}$ conducted the literature search; $\mathrm{AH}$ and $\mathrm{KT}$ collected the data; $\mathrm{AH}, \mathrm{KT}$, and $\mathrm{MS}$ analyzed and interpreted the data; $\mathrm{AH}, \mathrm{KT}$, and MS drafted the manuscript; all authors critically revised the manuscript. All authors read and approved the final manuscript.

\section{Funding}

This research was not funded by any funding agency.

Availability of supporting data

Not applicable.

Ethical approval and consent to participate

Not applicable.

\section{Consent for publication}

Not applicable.

\section{Competing interests}

The authors declare that they have no competing of interest.

\section{Appendix: Detailed search strategy PubMed}

"Delirium" AND "biomarkers", "delirium" AND "Acetylcholine", "Delirium" AND "Adenylate kinase", "Delirium" AND "Myokinase", "Delirium" AND "Albumin", "Delirium" AND "Amyloid", "Delirium" AND "ASAT", "Delirium" AND "Aspartate transaminase", "Delirium" AND "Aspartate aminotransferase", "Delirium" AND "AST", "Delirium" AND "BDNF", "Delirium" AND "Brainderived neurotrophic factor", "Delirium" AND "Cholezystokinine", "Delirium" AND "Cholinesterase", "Delirium" AND "Cortisol", "Delirium" AND "Creatine kinase", "Delirium" AND "Creatine phosphokinase", "Delirium" AND "Creatine kinase BB", "Delirium" AND "CK-BB", "Delirium" AND "CREB", "Delirium" AND "Cyclic AMP response element-binding protein", "Delirium" AND "CRP", "Delirium" AND "Dopamine", "Delirium" AND "Histamine H1", "Delirium" AND "Heat Shock Protein 70", "Delirium" AND "IL-2", "Delirium” AND "Interleukin-2", "Delirium" AND "IL-6", "Delirium" AND "Interleukin-6", "Delirium" AND "IL-8", "Delirium" AND "Interleukin-8", "Delirium" AND "IL-18", "Delirium" AND "Interleukin-18", "Delirium" AND "Lactate dehydrogenase", "Delirium" AND "Leptin", "Delirium" AND "Neopterin", "Delirium" AND "NSE", "Delirium" AND "Neuron specific enolase", "Delirium" AND "Phosphatidylinositol-3-kinases", "Delirium" AND "Phosphatidylinositol-4,5-bisphosphate 3-kinase", "Delirium" AND "Phosphatidylinositide 3-kinases", "Delirium" AND "PI3K", "Delirium" AND "PCT", "Delirium" AND "Procalcitonin", "Delirium" AND "Protein C", "Delirium" AND "S-100", "Delirium" AND "S-100beta", "Delirium" AND "S-100ß", "Delirium" AND "Calcium-binding protein B", "Delirium" AND "S100 protein", "Delirium" AND "SDNF",
"Delirium" AND "Mammalian striatal-derived neuronotrophic factor", "Delirium" AND "Striatal-derived neuronotrophic factor", "Delirium" AND "Neuronotrophic factor", "Delirium" AND "Thioredoxin", "Delirium" AND "TNF- $\alpha$, "Delirium" AND “TNF-alpha", "Delirium" AND "8-iso Prostaglandin F2 $\alpha$ ".

no limit [all fields].

\section{Cochrane}

"Delirium" AND "Biomarker", "Delirium" AND "Acetylcholine", "Delirium" AND "Adenylate kinase", "Delirium" AND "Myokinase", "Delirium" AND "Albumin", "Delirium" AND "Amyloid", "Delirium" AND "ASAT", "Delirium" AND "Aspartate transaminase", "Delirium" AND "Aspartate aminotransferase", "Delirium" AND "AST", "Delirium" AND "BDNF", "Delirium" AND "Brainderived neurotrophic factor", "Delirium" AND "Cholezystokinine", "Delirium" AND "Cholinesterase", "Delirium" AND "Cortisol", "Delirium" AND "Creatine kinase", "Delirium" AND "Creatine phosphokinase", "Delirium" AND "Creatine kinase BB", "Delirium" AND "CK-BB", "Delirium" AND "CREB", "Delirium" AND "Cyclic AMP response element-binding protein", "Delirium" AND "CRP", "Delirium" AND "Dopamine", "Delirium" AND "Histamine H1", "Delirium" AND "Heat Shock Protein 70", "Delirium" AND "IL-2", "Delirium" AND "Interleukin-2", "Delirium" AND "IL-6", "Delirium" AND "Interleukin-6", "Delirium" AND "IL-8", "Delirium" AND "Interleukin-8", "Delirium" AND "IL-18", "Delirium" AND "Interleukin-18", "Delirium" AND "Lactate dehydrogenase", "Delirium" AND "Leptin", "Delirium" AND "Neopterin", "Delirium" AND "NSE", "Delirium" AND "Neuron specific enolase", "Delirium" AND "Phosphatidylinositol-3-kinases", "Delirium" AND "Phosphatidylinositol-4,5-bisphosphate 3-kinase", "Delirium" AND "Phosphatidylinositide 3-kinases", "Delirium" AND "PI3K", "Delirium" AND "PCT", "Delirium" AND "Procalcitonin", "Delirium" AND "Protein C", "Delirium" AND "S-100", "Delirium" AND "S-100beta", "Delirium" AND "S-1008", "Delirium" AND "Calcium-binding protein B", "Delirium" AND “S100 protein", "Delirium” AND “SDNF", "Delirium" AND "Mammalian striatal-derived neuronotrophic factor", "Delirium" AND "Striatal-derived neuronotrophic factor", "Delirium" AND "Neuronotrophic factor", "Delirium" AND “Thioredoxin", "Delirium" AND "TNF- $\alpha$ ", "Delirium” AND “TNF-alpha”, "Delirium” AND "8-iso Prostaglandin F2 $\alpha$ ".

[full text], [human].

Identical search for: "Acute Brain Dysfunction" AND "XXX"; "Stroke" AND "XXX" AND "Delirium"; 
"Hemorrhagic Stroke" AND "XXX" AND "Delirium"; "Ischemic Stroke" AND "XXX" AND "Delirium"; "Traumatic Brain Injury" AND "XXX" AND "Delirium"; "Septic Encephalopathy" AND "XXX” AND "Delirium”.

\section{EMBASE/MEDLINE}

"Delirium" AND "Biomarker", "Delirium" AND "Acetylcholine", "Delirium" AND "Adenylate kinase", "Delirium" AND "Myokinase", "Delirium" AND "Albumin", "Delirium" AND "Amyloid", "Delirium" AND "ASAT", "Delirium" AND "Aspartate transaminase", "Delirium" AND "Aspartate aminotransferase", "Delirium" AND "AST", "Delirium" AND "BDNF", "Delirium" AND "Brainderived neurotrophic factor", "Delirium" AND "Cholezystokinine", "Delirium" AND "Cholinesterase", "Delirium" AND "Cortisol", "Delirium" AND "Creatine kinase", "Delirium" AND "Creatine phosphokinase", "Delirium" AND "Creatine kinase BB", "Delirium" AND "CK-BB", "Delirium" AND "CREB", "Delirium" AND "Cyclic AMP response element-binding protein", "Delirium" AND "CRP", "Delirium" AND "Dopamine", "Delirium" AND "Histamine H1", "Delirium" AND "Heat Shock Protein 70", "Delirium" AND "IL-2", "Delirium" AND "Interleukin-2", "Delirium" AND "IL-6", "Delirium" AND "Interleukin-6", "Delirium" AND "IL-8”, "Delirium” AND "Interleukin-8", "Delirium" AND "IL-18", "Delirium" AND "Interleukin-18", "Delirium" AND "LDH", "Delirium" AND "Lactate dehydrogenase", "Delirium" AND "Leptin", "Delirium" AND "Neopterin", "Delirium" AND "NSE", "Delirium" AND "Neuron specific enolase", "Delirium" AND "Phosphatidylinositol-3-kinases", "Delirium" AND "Phosphatidylinositol-4,5-bisphosphate 3-kinase", "Delirium" AND "Phosphatidylinositide 3-kinases", "Delirium" AND "PI3K", "Delirium" AND "PCT", "Delirium" AND "Procalcitonin", "Delirium" AND "Protein C", "Delirium" AND "S-100", "Delirium" AND "S-100beta", "Delirium" AND "S-100ß", "Delirium" AND "Calcium-binding protein B", "Delirium" AND "S100 protein", "Delirium" AND "SDNF", "Delirium" AND "Mammalian striatal-derived neuronotrophic factor", "Delirium" AND "Striatalderived neuronotrophic factor", "Delirium" AND "Neuronotrophic factor", "Delirium" AND "Thioredoxin", "Delirium” AND “TNF- $\alpha$, "Delirium” AND “TNF-alpha”, "Delirium" AND "8-iso Prostaglandin F2 $\alpha$ ".

Disease search, "search also as free text in all fields", "human", "English", source "EMBASE" and "Medline", for publication types "Article", "Article in press" and "Letter".

Example: Delirium AND biomarker AND ([article]/ lim OR [article in press]/lim OR [letter]/lim) AND [humans]/lim AND [english]/lim AND ([embase]/lim OR [medline]/lim).

\section{Author details}

1 Department for Anesthesia, Intensive Care and Emergency Medicine, SeeSpital, Horgen, Kilchberg, Switzerland. ${ }^{2}$ Institute for Anesthesia and Intensive Care, Hirslanden Klinik Zurich, Zurich, Switzerland. ${ }^{3}$ Department for Intensive Care, University Hospital Basel, Basel, Switzerland. ${ }^{4}$ Medical Faculty of the University of Basel, Basel, Switzerland. ${ }^{5}$ Department for Anesthesia, Prehospital Emergency Medicine and Pain Therapy, University Hospital Basel, Basel, Switzerland

Received: 6 June 2019 Accepted: 20 June 2019

Published online: 01 July 2019

\section{References}

1. Aitken SJ, Blyth FM, Naganathan V. Incidence, prognostic factors and impact of postoperative delirium after major vascular surgery: a metaanalysis and systematic review. Vasc Med. 2017;22(5):387-97.

2. McCusker J, Cole MG, Dendukuri N, Belzile E. Does delirium increase hospital stay? J Am Geriatr Soc. 2003;51(11):1539-46.

3. Bokeriia LA, Golukhova EZ, Polunina AG. Postoperative delirium in cardiac operations: microembolic load is an important factor. The Annals of thoracic surgery. 2009;88(1):349-50 (author reply 50-1).

4. Holmes J, House A. Psychiatric illness predicts poor outcome after surgery for hip fracture: a prospective cohort study. Psychol Med. 2000;30(4):921-9.

5. Nightingale S, Holmes J, Mason J, House A. Psychiatric illness and mortality after hip fracture. Lancet. 2001;357(9264):1264-5.

6. Gonzalez M, Martinez G, Calderon J, Villarroel L, Yuri F, Rojas C, et al. Impact of delirium on short-term mortality in elderly inpatients: a prospective cohort study. Psychosomatics. 2009:50(3):234-8.

7. Koster S, Hensens AG, Schuurmans MJ, van der Palen J. Consequences of delirium after cardiac operations. The Annals of thoracic surgery. 2012;93(3):705-11.

8. Marcantonio ER, Flacker JM, Michaels M, Resnick NM. Delirium is independently associated with poor functional recovery after hip fracture. J Am Geriatr Soc. 2000;48(6):618-24.

9. Sessler CN, Gosnell MS, Grap MJ, Brophy GM, O'Neal PV, Keane KA, et al. The Richmond Agitation-Sedation Scale: validity and reliability in adult intensive care unit patients. Am J Respir Crit Care Med. 2002;166(10):1338-44.

10. Leslie DL, Marcantonio ER, Zhang Y, Leo-Summers L, Inouye SK. One-year health care costs associated with delirium in the elderly population. Arch Intern Med. 2008:168(1):27-32.

11. Devlin JW, Skrobik Y, Gelinas C, Needham DM, Slooter AJC, Pandharipande PP, et al. Clinical practice guidelines for the prevention and management of pain, agitation/sedation, delirium, immobility, and sleep disruption in adult patients in the ICU. Crit Care Med. 2018;46(9):e825-73.

12. Sockalingam S, Parekh N, Bogoch II, Sun J, Mahtani R, Beach C, et al. Delirium in the postoperative cardiac patient: a review. J Card Surg. 2005;20(6):560-7.

13. Hudetz JA, Patterson KM, lqbal Z, Gandhi SD, Byrne AJ, Hudetz AG, et al. Ketamine attenuates delirium after cardiac surgery with cardiopulmonary bypass. J Cardiothorac Vasc Anesth. 2009;23(5):651-7.

14. Chanques G, Ely EW, Garnier O, Perrigault F, Eloi A, Carr J, et al. The 2014 updated version of the Confusion Assessment Method for the Intensive Care Unit compared to the 5th version of the Diagnostic and Statistical Manual of Mental Disorders and other current methods used by intensivists. Ann Intensive Care. 2018;8(1):33.

15. Maldonado JR. Delirium in the acute care setting: characteristics, diagnosis and treatment. Crit Care Clin. 2008;24(4):657-722 (vii).

16. Neuville M, El-Helali N, Magalhaes E, Radjou A, Smonig R, Soubirou JF, et al. Systematic overdosing of oxa- and cloxacillin in severe infections treated in ICU: risk factors and side effects. Ann Intensive Care. 2017;7(1):34.

17. Wang PP, Huang E, Feng X, Bray CA, Perreault MM, Rico P, et al. Opioidassociated iatrogenic withdrawal in critically ill adult patients: a multicenter prospective observational study. Ann Intensive Care. 2017;7(1):88.

18. Hollinger A, Siegemund M, Goettel N, Steiner LA. Postoperative delirium in cardiac surgery: an unavoidable menace? J Cardiothorac Vasc Anesth. 2015;29(6):1677-87. 
19. Khan BA, Zawahiri M, Campbell NL, Boustani MA. Biomarkers for delirium-a review. J Am Geriatr Soc. 2011;59(Suppl 2):S256-61.

20. Androsova G, Krause R, Winterer G, Schneider R. Biomarkers of postoperative delirium and cognitive dysfunction. Front Aging Neurosci. 2015;7:112.

21. Elie M, Cole MG, Primeau FJ, Bellavance F. Delirium risk factors in elderly hospitalized patients. J Gen Intern Med. 1998;13(3):204-12.

22. Stocchetti N, Taccone FS, Citerio G, Pepe PE, Le Roux PD, Oddo M, et al. Neuroprotection in acute brain injury: an up-to-date review. Crit Care. 2015;19:186.

23. Larsen KA, Kelly SE, Stern TA, Bode RH Jr, Price LL, Hunter DJ, et al. Administration of olanzapine to prevent postoperative delirium in elderly joint-replacement patients: a randomized, controlled trial. Psychosomatics. 2010;51(5):409-18.

24. Guo Y, Jia P, Zhang J, Wang $X$, Jiang $H$, Jiang W. Prevalence and risk factors of postoperative delirium in elderly hip fracture patients. J Int Med Res. 2016;44(2):317-27.

25. Capri M, Yani SL, Chattat R, Fortuna D, Bucci L, Lanzarini C, et al. Pre-operative, high-IL-6 blood level is a risk factor of post-operative delirium onset in old patients. Front Endocrinol (Lausanne). 2014;5:173.

26. Lee JK, Park YS. Delirium after spinal surgery in Korean population. Spine (Phila Pa 1976). 2010;35(18):1729-32.

27. Sun $L$, Jia $P$, Zhang J, Zhang $X$, Zhang $Y$, Jiang $H$, et al. Production of inflammatory cytokines, cortisol, and Abeta1-40 in elderly oral cancer patients with postoperative delirium. Neuropsychiatr Dis Treat. 2016;12:2789-95.

28. Cerejeira J, Nogueira V, Luis P, Vaz-Serra A, Mukaetova-Ladinska EB. The cholinergic system and inflammation: common pathways in delirium pathophysiology. J Am Geriatr Soc. 2012;60(4):669-75.

29. Vasunilashorn SM, Ngo LH, Chan NY, Zhou W, Dillon ST, Otu HH, et al. Development of a dynamic multi-protein signature of postoperative delirium. The Journals of Gerontology Series A, Biological Sciences and Medical Sciences. 2018;74:261-8.

30. Vasunilashorn SM, Dillon ST, Inouye SK, Ngo LH, Fong TG, Jones RN, et al. High C-reactive protein predicts delirium incidence, duration, and feature severity after major noncardiac surgery. J Am Geriatr Soc. 2017;65(8):e109-16.

31. Cizginer S, Marcantonio E, Vasunilashorn S, Pascual-Leone A, Shafi M, Schmitt EM, et al. The cognitive reserve model in the development of delirium: the successful aging after elective surgery study. J Geriatr Psychiatry Neurol. 2017;30(6):337-45.

32. Beloosesky Y, Grinblat J, Pirotsky A, Weiss A, Hendel D. Different C-reactive protein kinetics in post-operative hip-fractured geriatric patients with and without complications. Gerontology. 2004;50(4):216-22.

33. Xin X, Xin F, Chen X, Zhang Q, Li Y, Huo S, et al. Hypertonic saline for prevention of delirium in geriatric patients who underwent hip surgery. J Neuroinflammation. 2017; 14(1):221

34. Jia Y, Jin G, Guo S, Gu B, Jin Z, Gao X, et al. Fast-track surgery decreases the incidence of postoperative delirium and other complications in elderly patients with colorectal carcinoma. Langenbecks Arch Surg. 2014;399(1):77-84.

35. van Munster BC, Korevaar JC, Zwinderman AH, Levi M, Wiersinga WJ, De Rooij SE. Time-course of cytokines during delirium in elderly patients with hip fractures. J Am Geriatr Soc. 2008;56(9):1704-9.

36. Chen XW, Shi JW, Yang PS, Wu ZQ. Preoperative plasma leptin levels predict delirium in elderly patients after hip fracture surgery. Peptides. 2014;57:31-5

37. Wu XM, Xu WC, Yu YJ, Han L, Zhang J, Yang LJ. Postoperative serum thioredoxin concentrations correlate with delirium and cognitive dysfunction after hip fracture surgery in elderly patients. Clinica Chimica Acta; International Journal of Clinical Chemistry. 2017;466:93-7.

38. Zheng YB, Ruan GM, Fu JX, Su ZL, Cheng P, Lu JZ. Postoperative plasma 8-iso-prostaglandin F2alpha levels are associated with delirium and cognitive dysfunction in elderly patients after hip fracture surgery. Clinica chimica acta; international journal of clinical chemistry. 2016;455:149-53.

39. Bakker RC, Osse RJ, Tulen JH, Kappetein AP, Bogers AJ. Preoperative and operative predictors of delirium after cardiac surgery in elderly patients. Eur J Cardiothorac Surg. 2012;41(3):544-9.

40. Chu CS, Liang CK, Chou MY, Lin YT, Hsu CJ, Chu CL, et al. Lack of association between pre-operative insulin-like growth factor-1 and the risk of post-operative delirium in elderly chinese patients. Psychiatry Investig. 2016;13(3):327-32.

41. Lee HJ, Hwang DS, Wang SK, Chee IS, Baeg S, Kim JL. Early assessment of delirium in elderly patients after hip surgery. Psychiatry Investig. 2011;8(4):340-7.

42. Egberts A, Osse RJ, Fekkes D, Tulen JHM, van der Cammen TJM, MattaceRaso FUS. Differences in potential biomarkers of delirium between acutely ill medical and elective cardiac surgery patients. Clin Interv Aging 2019;14:271-81.

43. Zhang DF, Su X, Meng ZT, Cui F, Li HL, Wang DX, et al. Preoperative severe hypoalbuminemia is associated with an increased risk of postoperative delirium in elderly patients: results of a secondary analysis. J Crit Care. 2018:44:45-50.

44. Gao F, Zhang Q, Li Y, Tai Y, Xin X, Wang X, et al. Transcutaneous electrical acupoint stimulation for prevention of postoperative delirium in geriatric patients with silent lacunar infarction: a preliminary study. Clin Interv Aging. 2018;13:2127-34.

45. Slor CJ, Witlox J, Adamis D, Jansen R, Houdijk APJ, van Gool WA, et al. The trajectory of C-reactive protein serum levels in older hip fracture patients with postoperative delirium. Int J Geriatr Psychiatry. 2019; https://doi. org/10.1002/gps.5139.

46. Miao S, Shen P, Zhang Q, Wang H, Shen J, Wang G, et al. Neopterin and mini-mental state examination scores, two independent risk factors for postoperative delirium in elderly patients with open abdominal surgery. J Cancer Res Ther. 2018;14(6):1234-8.

47. Plaschke K, Petersen KA, Frankenhauser S, Weigand MA, Kopitz J, Bardenheuer $\mathrm{HJ}$. The impact of plasma cholinergic enzyme activity and other risk factors for the development of delirium in patients receiving palliative care. J Pain Symptom Manage. 2016;52(4):525-32.

48. Brum C, Stertz L, Borba E, Rumi D, Kapczinski F, Camozzato A. Association of serum brain-derived neurotrophic factor (BDNF) and tumor necrosis factor-alpha (TNF-alpha) with diagnosis of delirium in oncology inpatients. Rev Bras Psiquiatr. 2015;37(3):197-202.

49. Egberts A, Mattace-Raso FU. Increased neutrophil-lymphocyte ratio in delirium: a pilot study. Clin Interv Aging. 2017;12:1115-21.

50. Ritchie $C W$, Newman TH, Leurent B, Sampson EL. The association between C-reactive protein and delirium in 710 acute elderly hospital admissions. Int Psychogeriatr. 2014;26(5):717-24.

51. Kuswardhani RAT, Sugi YS. Factors related to the severity of delirium in the elderly patients with infection. Gerontol Geriatr Med. 2017;3:2333721417739188.

52. Nguyen DN, Huyghens L, Schiettecatte J, Smitz J, Vincent JL. High prolactin levels are associated with more delirium in septic patients. J Crit Care. 2016;33:56-61.

53. van Munster BC, Zwinderman AH, de Rooij SE. Genetic variations in the interleukin- 6 and interleukin- 8 genes and the interleukin- 6 receptor gene in delirium. Rejuvenation Res. 2011;14(4):425-8.

54. Sanchez JC, Ospina JP, Gonzalez MI. Association between leptin and delirium in elderly inpatients. Neuropsychiatr Dis Treat. 2013;9:659-66.

55. Tune LE, Damlouji NF, Holland A, Gardner TJ, Folstein MF, Coyle JT. Association of postoperative delirium with raised serum levels of anticholinergic drugs. Lancet. 1981;2(8248):651-3.

56. Inouye SK. Delirium in older persons. N Engl J Med. 2006;354(11):1157-65

57. Inouye SK, Ferrucci L. Elucidating the pathophysiology of delirium and the interrelationship of delirium and dementia. The journals of gerontology Series A, Biological sciences and medical sciences. 2006;61(12):1277-80

58. Flukiger J, Hollinger A, Speich B, Meier V, Tontsch J, Zehnder T, et al. Dexmedetomidine in prevention and treatment of postoperative and intensive care unit delirium: a systematic review and meta-analysis. Ann Intensive Care. 2018;8(1):92.

59. Riegger $H$, Hollinger A, Seifert B, Toft $K$, Blum A, Zehnder T, et al. Baden Prevention and Reduction of Incidence of Postoperative Delirium Trial (PRIDe): a phase IV multicenter, randomized, placebo-controlled, double-blind clinical trial of ketamine versus haloperidol for prevention of postoperative delirium. Trials. 2018;19(1):142.

60. Hshieh TT, Fong TG, Marcantonio ER, Inouye SK. Cholinergic deficiency hypothesis in delirium: a synthesis of current evidence. The journals of gerontology Series A, Biological sciences and medical sciences. 2008:63:764-72. 
61. Adamis D, Treloar A, Martin FC, Macdonald AJ. A brief review of the history of delirium as a mental disorder. Hist Psychiatry. 2007;18(72 Pt 4):459-69.

62. Fong TG, Davis D, Growdon ME, Albuquerque A, Inouye SK. The interface between delirium and dementia in elderly adults. Lancet Neurol. 2015;14(8):823-32.

63. Hughes CG, Pandharipande PP, Thompson JL, Chandrasekhar R, Ware LB, Ely EW, et al. Endothelial activation and blood-brain barrier injury as risk factors for delirium in critically ill patients. Crit Care Med. 2016;44(9):e809-17

64. Hughes CG, Patel MB, Brummel NE, Thompson JL, McNeil JB, Pandharipande PP, et al. Relationships between markers of neurologic and endothelial injury during critical illness and long-term cognitive impairment and disability. Intensive Care Med. 2018;44(3):345-55.

65. Ritter C, Tomasi CD, Dal-Pizzol F, Pinto BB, Dyson A, de Miranda AS, et al. Inflammation biomarkers and delirium in critically ill patients. Crit Care. 2014;18(3):R106.

66. Dittrich T, Tschudin-Sutter S, Widmer AF, Ruegg S, Marsch S, Sutter R. Risk factors for new-onset delirium in patients with bloodstream infections: independent and quantitative effect of catheters and drainages-a fouryear cohort study. Ann Intensive Care. 2016;6(1):104.
67. Girard TD, Ware LB, Bernard GR, Pandharipande PP, Thompson JL, Shintani AK, et al. Associations of markers of inflammation and coagulation with delirium during critical illness. Intensive Care Med. 2012;38(12):1965-73.

68. van den Boogaard M, Kox M, Quinn KL, van Achterberg T, van der Hoeven JG, Schoonhoven L, et al. Biomarkers associated with delirium in critically ill patients and their relation with long-term subjective cognitive dysfunction; indications for different pathways governing delirium in inflamed and noninflamed patients. Crit Care. 2011;15(6):R297.

\section{Publisher's Note}

Springer Nature remains neutral with regard to jurisdictional claims in published maps and institutional affiliations.

\section{Submit your manuscript to a SpringerOpen ${ }^{\circ}$ journal and benefit from:}

- Convenient online submission

- Rigorous peer review

- Open access: articles freely available online

- High visibility within the field

- Retaining the copyright to your article

Submit your next manuscript at $\boldsymbol{\nabla}$ springeropen.com 